\title{
Implementation of Computational Aids in Diels-Alder Reactions: Regioselectivity and Stereochemistry of Adduct Formation
}

\author{
Jiyoung Jung \\ Department of Science, \\ Penn State University \\ Worthington Scranton, PA 18512 \\ 1-570-963-2559 \\ juj23@psu.edu
}

\author{
Susan Zirpoli \\ Department of Chemistry, \\ Slippery Rock University \\ Slippery Rock, PA 16057 \\ 1-724-738-2716 \\ susan.zirpoli@sru.edu
}

\author{
Glenn Slick \\ Department of Science, \\ Penn State University \\ Worthington Scranton, PA 18512 \\ 1-570-963-2559 \\ gss5127@psu.edu
}

\begin{abstract}
The Diels-Alder reaction is one of the most well-known organic reactions and is widely used for six-membered ring formation. Regio- and stereo-selective Diels-Alder reactions have been emphasized in various areas including pharmaceutical and polymer industries. However, covering the theoretical background of such reactions in an undergraduate class is challenging because the interactions between molecular orbitals is poorly visualized for students. Especially when dealing with polycyclic aromatic hydrocarbons (PAHs) and asymmetric compounds, the complexity of regio- and stereo-selectivity becomes more pronounced. Herein we utilized web-based computational tools (WebMO) to visualize the HOMO-LUMO of each reaction component and their interaction to form chemical bonds. In this study we demonstrated the incorporation of computational aids into a Diels-Alder laboratory class dramatically facilitates students' understanding of several important concepts including frontier orbital theory, thermodynamics of the reaction, three-dimensional visualization, and so on. The assessment of teaching effectiveness prior to and after implementation of computational aids into Diels-Alder reactions will also be discussed in this manuscript.
\end{abstract}

\section{CCS Concepts}

- Social and Professional Topics $\rightarrow$ Computational Science and Engineering Education.

\section{Keywords}

Diels-Alder reaction, Molecular orbital, Geometry optimization, Computational calculation, WebMO, Education, Undergraduate laboratory.
Permission to make digital or hard copies of all or part of this work for personal or classroom use is granted without fee provided that copies are not made or distributed for profit or commercial advantage and that copies bear this notice and the full citation on the first page. To copy otherwise, or republish, to post on servers or to redistribute to lists, requires prior specific permission and/or a fee. Copyright CJOCSE, a supported publication of the Shodor Education Foundation Inc.

DOI: https://doi.org/10.22369/issn.2153-4136/8/1/1

\section{INTRODUCTION}

As computational chemistry has significantly contributed to chemical research, many chemistry programs across the country now incorporate computational chemistry in their undergraduate curriculum [1-4]. In the last decade, leveraging such modern technology including open-source computational tools into actual undergraduate laboratories has been published in journals. Inspired by such efforts $[5,6]$, we recently implemented a web-based computational aid (WebMO, MOPAC with PM3) in our organic chemistry laboratory course where students have difficulty in understanding physical organic chemistry concepts.

Diels-Alder cycloaddition reactions are widely used in synthetic organic chemistry since it was first described by Otto Diels and Kurt Alder in 1928 [7, 8]. Due to its interesting mechanism and accessibility to upper-level undergraduate coursework, there have been a variety of reports which involve Diels-Alder reaction in undergraduate laboratory classes [9-12]. The challenges of effective teaching the Diels-Alder reaction, however, stem from understanding the three-dimensional perspective of the molecules and molecular orbitals in an adduct formation which most undergraduate students have poorly understood in class. Cycloadditions such as the Diels-Alder reaction involve the concerted forming and breaking of bonds within a closed ring. In order to understand the reaction mechanism, conservation of orbital symmetry has been used to predict how cycloaddition can occur and what adducts will be produced. Due to complexity including prediction of regioselectivity, stereochemistry and reactive positions, these concepts tend to be one of the most challenging sections to comprehend for undergraduate students. Such complexity becomes more pronounced when students deal with polycyclic aromatic hydrocarbons such as anthracene which is a well-known diene in undergraduate laboratory classes [12]. In this manuscript the integration of web-based computational aids with the hands-on synthetic experiment and its effectiveness in facilitating students' understanding will be discussed.

\section{EXPERIMENTAL DESIGN}

The computational procedure of this study is based on the exemplified lab exercises which can be found in the website of Computational Chemistry for Chemistry Educators (CCCE) and the CCCE workshop [13, 14]. To evaluate the effectiveness of computational aids in understanding a Diels-Alder reaction in the sophomore level class, the study was conducted for eight semesters and observed over eighty students who were enrolled in both the lecture and the corresponding laboratory sections in each semester. 
This particular lab was achieved over a series of five assignments which consisted of one class lecture and two lab periods as outlined in Figure 1.

Lecture of Diels-Alder Reaction

\begin{tabular}{|c|}
\hline Pre-lab Assignment \\
\hline Introducing WebMO (lab-lecture) \\
\hline Post-lab Assignment \\
\hline $\begin{array}{l}\text { Synthesis and Analysis of } \\
\text { Diels-Alder adduct }\end{array}$ \\
\hline Final Lab report \\
\hline
\end{tabular}

Figure 1. Class design for computational-aid of Diels-Alder reaction experiment. Gray color indicates that Diels-Alder reaction is covered in a regular organic chemistry class.

The class design consists of two homework assignments (pre-lab and post-lab assignments) and one lab-lecture and the actual performance of Diels-Alder reaction. Students were first introduced to Diels-Alder reactions in a regular organic chemistry lecture prior to the pre-lab assignment. The assignment asked a series of fundamental questions pertaining to the identification of the diene and dienophile, location of reactive sites, predicting products and sketching reactants' molecular orbitals. After completing the initial assignment, students were introduced to computational calculations using WebMO software which can calculate geometric optimization, molecular orbitals, and heats of formation, and etc. Using the information collected by computational aids in hand, the post-lab assignment addressed the similar set of questions with anthracene and maleic anhydride which are used as reactants in the actual Diels-Alder reaction experiment. (Table 2; The actual prelab and post-lab assignments can also be found in Supporting Material). After completing the computational calculations in the post-lab assignment, reaction between anthracene and maleic anhydride was performed in the laboratory. Therefore students have much better understanding about the Diels-Alder reaction by studying the theoretical calculations before they actually conduct the synthetic experiment. The product of the reaction was then identified using a melting point determination and NMR spectroscopy analysis. Experimental detail including synthetic procedure and discussion points is attached in Supporting Material.

\section{COMPUTATIONAL TOOLS}

WebMO is a freely available web-based tool which provides an access to multiple computational engines such as MOPAC, Gaussian, and DFT [15]. In this experiment, the MOPAC engine and PM3 theory was used to obtain molecular orbitals and geometric optimization of the proposed dienes/dienophiles and products. Once a calculation is completed, optimized geometry, heat of formation energy, energy of molecular orbital, and visualized molecular orbitals become available in the viewer window. Detailed tutorial and troubleshooting of using WebMO is also available in the website (http://www.webmo.net).

\section{RESULTS AND DISCUSSIONS 4.1 Diels-Alder Reaction}

Predicting regioselectivity and stereochemistry of asymmetric dienes-dienophiles is commonly performed by identifying electron withdrawing and donating groups followed by a drawing of the respective resonance structures (Figure 2a). In addition to this traditional approach, the molecular orbital calculation was conducted on the asymmetric Diels-Alder reactions. In this study, acrylaldehyde and 2-methoxy cyclohexa-1,3-diene were used as a dienophile and a diene, respectively. The frontier orbital approach is a good way to understand these [4+2] cycloaddition reactions. The highest occupied molecular orbital (HOMO) of 2-methoxy cyclohexa-1,3-diene and the lowest unoccupied molecular orbital (LUMO) of acrylaldehyde were identified by evaluating electron occupancy in each orbital. Matching orbitals with the largest lobes in the $\mathrm{HOMO}_{\text {diene }}$ and $\mathrm{LUMO}_{\text {dienophile }}$ can aid in visualizing the formation of more favorable transition state with a six-membered ring which, in turn, provides the major product. As shown in Figure $2 \mathrm{~b}$, the phases of the interacting orbitals are also color coded to help students to match lobes with the same sign and interact to form chemical bonds.
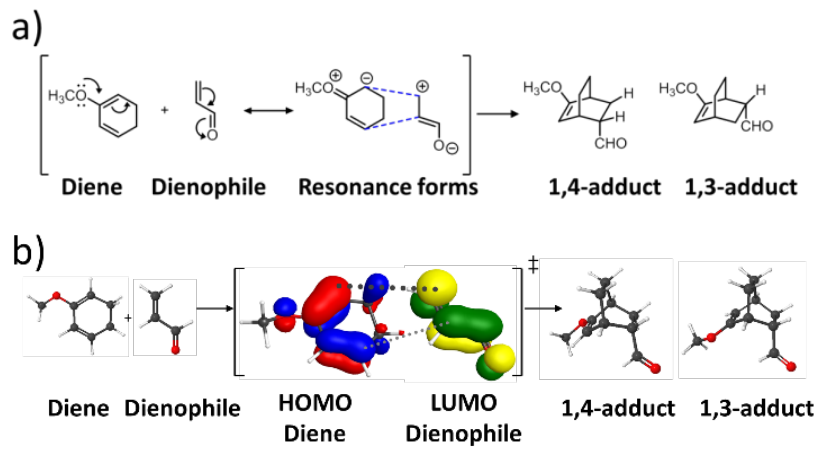

Figure 2. Reaction scheme between acrylaldehyde and 2methoxy cyclohexa-1,3-diene, a) Regio-selective adduct prediction by charge-separated resonance structures, b) HOMO-LUMO interaction and three-dimensional view of both adducts calculated by MOPAC with PM3.

After deducing which orbitals were most likely to form a bond during the Diels-Alder reaction, both potential adducts were geometrically optimized. The enthalpy changes for the reactions were calculated to determine which adduct would be enthalpically favored (Table 1). The heat of reaction revealed that the 1,4-adduct is slightly favored by $0.3 \mathrm{kcal} / \mathrm{mol}$ which is consistent with experimental results [16].

Table 1. Enthalpy change for Diels-Alder reaction ${ }^{\ddagger}$

\begin{tabular}{|c|c|c|c|c|}
\hline Name & Diene & Dienophile & Adduct & $\begin{array}{c}\Delta \mathbf{H}_{\mathbf{r n n}} \\
(\mathbf{k c a l} / \mathbf{m o l}) *\end{array}$ \\
\hline 1,4-adduct & -17.26 & -18.31 & -68.45 & -32.89 \\
\hline 1,3-adduct & -17.26 & -18.31 & -68.17 & -32.61 \\
\hline
\end{tabular}

fOnly enthalpic contribution was considered.

* Data is calculated by MOPAC with PM3. 
Although the favorable formation of 1,4-adduct is largely governed by the transition state interaction as shown in the resonance structures of diene-dienophile (Figure 2a), students can readily evaluate the regioselectivity between two potential adducts through visually evaluating the HOMO-LUMO interaction. Using the molecular orbital diagrams in conjunction with the thermodynamic results allowed not only a visual evaluation but also a quantitative approach in determining a regioselective product.

\subsection{Cycloaddition of Polycyclic Aromatic Hydrocarbons}

Although the Diels-Alder reaction between anthracene and maleic anhydride is a well-known reaction, often rationalizing how to predict the reaction sites on fused-ring systems is challenging in undergraduate laboratory classes (Figure 3a). The regioselectivity of this reaction can best be understood by using aromaticity, so the reaction occurs at $\mathrm{C} 9$ and $\mathrm{C} 10$ site where the weakest benzenoid character exists. The structures with more fused rings tend to have lower resonance energies per $\pi$-electron compared to benzene. Because the structures with fewer rings are more stable, cycloaddition reaction of anthracene where three rings are fused together occurs at an internal ring over a terminal ring to give a more stable product. With computational aids, however, students can visually approach which carbon atoms in the diene are involved in the cycloaddition. On the HOMO of anthracene, the carbon C9 and $\mathrm{C} 10$ on the middle cycle possess the largest lobes indicating the most reactive site (Figure $3 \mathrm{~b}$ ). Connecting with the largest lobes designated in maleic anhydride gives the anticipated product, 9-10dihydroanthracene- $9,10-\alpha-\beta$ succinic anhydride.

Another challenge for students to understand would be predicting the three-dimensional geometry of the final adduct. As shown in Figure $3 \mathrm{c}$, the optimized geometry of the adduct was obtained by MOPAC, and clearly displays that the two hydrogen atoms in maleic anhydride retain cis-position. Additionally, the puckered structure of middle cycle indicates the change from $\mathrm{sp}^{2}$ to $\mathrm{sp}^{3}$ hybridization upon the formation of the adduct.

a)
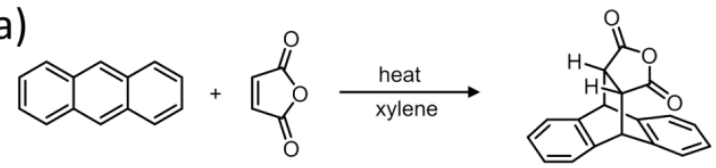

Anthracene Maleic anhydride

9,10-dihydroanthracene-9,10$\alpha-\beta$-succinic anhydride b)

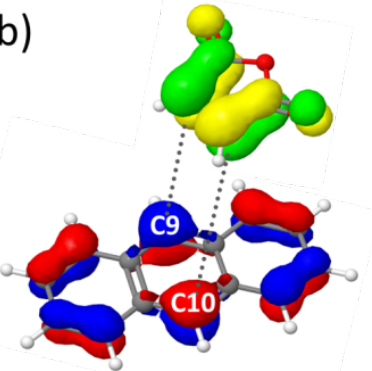

c)

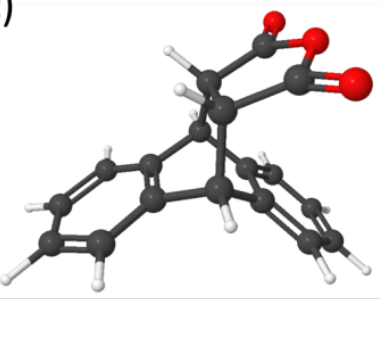

Figure 3. a) Diels-Alder Reaction between maleic anhydride (dienophile) and anthracene (diene), b) Schematic HOMOLUMO interaction, c) Optimized geometry of the Diels-Alder adduct.

Generating an energy level diagram with calculated molecular orbital energies of the diene and dienophile facilitated further visualization of the HOMO-LUMO interaction. As taught in class, the strongest interaction should be between the $\mathrm{HOMO}_{\text {diene }}$ and the $\mathrm{LUMO}_{\text {dienophile }}$ because of the smaller energy gap compared to the other interaction between the $\mathrm{LUMO}_{\text {diene }}$ and $\mathrm{HOMO}_{\text {dienophile }}$. With a smaller HOMO-LUMO energy gap, the orbitals interact to a great extent in the transition state, which reduces the energy barrier between the reactants and the product. Consistent with the lesson from the lecture, the energy gap between $\mathrm{HOMO}_{\text {diene }}$ LUMO $_{\text {dienophile }}(154.53 / \mathrm{mol})$ is unambiguously smaller than $\mathrm{HOMO}_{\text {dienophile }}-\mathrm{LUMO}_{\text {diene }}(247.65 \mathrm{kcal} / \mathrm{mol})$, which points out another important concept of frontier orbital interaction upon the cyclization (Figure 4).

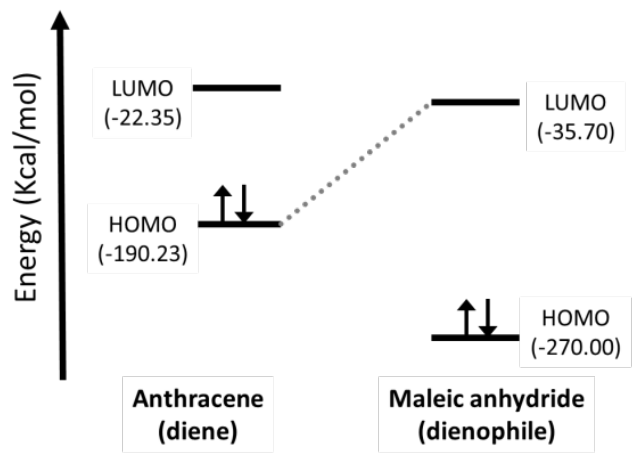

Figure 4. Frontier orbital energy diagram of maleic anhydride and anthracene.

Furthermore, the overall $\Delta \mathrm{H}_{\mathrm{rxn}}$ was calculated to be -32.9524 $\mathrm{kcal} / \mathrm{mol}$ which is the energy difference between anthracene $(61.5035 \mathrm{kcal} / \mathrm{mol}) /$ maleic anhydride $(-90.1541 \mathrm{kcal} / \mathrm{mol})$ and adduct $(-61.6030 \mathrm{kcal} / \mathrm{mol})$. The heat of reaction between reactants and product through the calculations allowed students to predict that the product will be enthalpically favored in the cycloaddition prior to the hands-on experiment.

\subsection{Assessment of Effectiveness of Computational Aids}

As described in the Class design (Figure 1), the effectiveness of computational aids was assessed by comparison between pre-lab assignment and post-lab assignment, which is tabulated in Table 2. Overall the post-lab assignment results showed markedly improved scores compared to the results in all questions prior to the implementation of computational visualization.

Table 2. Comparison between Pre-lab and Post-lab assignment results (prior to and after implementation of computational aids).

\begin{tabular}{|c|c|c|}
\hline \multirow{2}{*}{ Question } & \multicolumn{2}{|c|}{$\begin{array}{c}\text { Percentage Correct } \\
\text { Response }\end{array}$} \\
\cline { 2 - 3 } & $\begin{array}{c}\text { Pre-lab } \\
\text { assignment }\end{array}$ & $\begin{array}{c}\text { Post-lab } \\
\text { assignment }\end{array}$ \\
\hline Identify the Diene and Dienophile & 98 & 100 \\
\hline Predict reactive site in Dienophile & 88 & 89 \\
\hline Predict reactive site in Diene & 27 & 86 \\
\hline $\begin{array}{c}\text { Sketch HOMO-LUMO energy } \\
\text { diagram }\end{array}$ & 34 & 73 \\
\hline $\begin{array}{c}\text { Draw Diels-Alder product } \\
\text { (including stereochemistry) }\end{array}$ & 23 & 71 \\
\hline
\end{tabular}


Regardless of the computational analysis, most students correctly identified which components of a reaction were either diene or dienophile. Once diene and dienophile had been assigned, predicting the reaction sites of the dienophile was straightforward. It is presumably due to the fact that only one carbon-carbon double bond is present in maleic anhydride.

Finding the reactive carbons in the diene, however, becomes more challenging because of the highly conjugated structure of anthracene. The structure of anthracene gave mainly two choices of reaction sites, the middle cycle vs outer cycle. The majority of incorrect answers (73\%) in pre-lab assignment were assigning the reactive site at the outer cycle of anthracene because they considered less steric hindrance for the cyclization at the outer cycle as shown in students' final reports.

In the post-lab assignment, after utilizing visual aids from MOPAC, the percentage of correct response was dramatically increased $(27 \%$ to $86 \%$ ). It is because modeling the HOMO of anthracene clearly provides more information of which atoms have the right phase and largest lobe to interact with the LUMO of maleic anhydride. Therefore, it is evident that computational aids facilitated the students in properly identifying the most reactive carbons of fused ring systems.

Understanding the interaction between HOMO and LUMO during a Diels-Alder reaction was another challenging concept which resulted in only $34 \%$ of students correctly drawing the energy diagrams in the pre-lab assignment. Many students had difficulty in understanding why the interaction between $\mathrm{HOMO}_{\text {diene- }}$ $\mathrm{LUMO}_{\text {dienophile }}$ is favorable. It is presumably because generating a molecular orbital diagram was not a topic heavily emphasized in an undergraduate level class so that students are less familiar with molecular orbital or frontier orbital concepts. After using computational calculations which give molecular orbital energy levels in the numerical values (Figure 4) and visualized images of HOMO/LUMO with specific phases and sizes (Figure 3), students had a much better understanding of how the molecular orbitals were interacting and forming chemical bonds. This visual comprehension of molecular orbital theory transitioned into a more accurate molecular orbital diagram in the post-lab assignment.

Finally, only $23 \%$ of students were able to draw a correct chemical structure of the Diels-Alder product in the pre-lab assignment. There were mainly three categories of incorrect structures; i) wrong regioselectivity, i.e., bicycle formation with outer cycle of anthracene, ii) incorrect or no stereochemistry (cis- vs transhydrogen of maleic anhydride, iii) flat (unpuckered) structure of the fused bicycle. The majority of incorrect answers stemmed from the incorrectly assigned regioselectivity. It can be understood that students would not be able to draw the final product structure correctly once they identified incorrect reaction sites. However, it should be noted that besides the adduct formation with wrong regioselectivity, we found other two types of errors which are from the lack of three-dimensional understanding. In other words, students found a difficulty in assigning stereochemistry and structural transition from $\mathrm{sp}^{2}$ to $\mathrm{sp}^{3}$ hybridization. After obtaining the geometrically optimized adduct structure by molecular modeling, students had a better sense of a molecules geometric configuration in a three dimensional space, which translated into highly improved scores of the adduct stereochemistry in the postlab assignment. Furthermore, such structural information was also confirmed by NMR spectroscopy after the synthesis of the DielsAlder adduct. Therefore the results indicate that the implementation of computational analysis leverages students' understanding of many important concepts of physical organic chemistry.

\section{CONCLUSION}

In this study, we demonstrated that computational aids such as WebMO can be introduced into undergraduate level classes and facilitate students' better understanding of Diels-Alder reactions. Combinations of multiple concepts in chemistry often require quite complicated design of classes with multiple separated sections. The Diels-Alder reaction is a well-established example utilized in the undergraduate organic chemistry laboratory. By incorporating computational aids into this particular laboratory class, students can be exposed to several important concepts including thermodynamics, frontier orbital theory, stereochemistry, and so on. We also observed such visualization increased students' engagement in the course, which is presumably because they are more familiarized with today's technology. Harmonization of synthetic chemistry lab with computational analysis to demonstrate how physical chemistry can provide "visible" understanding is very important. It is, however, equally important for students to realize that computational results cannot solely be used to answer the questions. Further efforts to develop classes with highly efficient and effective teaching tools associated with computational analysis are ongoing in our department.

\section{ACKNOWLEDGMENTS}

We gratefully acknowledge the Shodor Education Foundation for the assistance of utilizing WebMO. And we specially acknowledge to the students who participated in this study at Penn State University at Worthington Scranton and Slippery Rock University.

\section{REFERENCES}

[1] Nassabeh, N.; Tran, M., and Fleming, P. E. 2014. Dissociation of the Ethyl Radical: An Exercise in Computational Chemistry. J. Chem. Edu. 91, 1248-1253. http://pubs.acs.org/doi/pdf/10.1021/ed4007748

[2] Perri, M. J. and Weber, S. H. 2014. Web-Based Job Submission Interface for the GAMESS Computational Chemistry Program. J. Chem. Edu. 91, 2206-2208. http://pubs.acs.org/doi/pdf/10.1021/ed5004228

[3] Albrecht, B. 2014. Computational Chemistry in the Undergraduate Laboratory: A Mechanistic Study of the Wittig Reaction. J. Chem. Edu. 91, 2182-2185. http://pubs.acs.org/doi/pdf/10.1021/ed400008d

[4] McNaught, I. J. 2011. Testing and Extending VSEPR with WebMO and MOPAC or GAMESS. J. Chem. Edu. 88, 421425. http://pubs.acs.org/doi/pdf/10.1021/ed900038a

[5] Rowley, C. N.; Woo, T. K., and Mosey, N. J. 2009. A Computational Experiment of the Endo versus Exo Preference in a Diels-Alder Reaction. J. Chem. Edu. 86, 199-201. http://pubs.acs.org/doi/pdf/10.1021/ed086p199.

[6] Palmer, D. R. J. 2004. Integration of Computational and Preparative Techniques To Demonstrate Physical Organic Concepts in Synthetic Organic Chemistry: An Example Using Diels-Alder Reactions. J. Chem. Edu. 81, 1633-1635. http://pubs.acs.org/doi/pdf/10.1021/ed081p1633

[7] Diels, O., and Alder, K. 1928. Synthesen in der hydroaromatischen Reihe. Justus Liebigs Ann. Chem. 460, 98-122. http://onlinelibrary.wiley.com/doi/10.1002/jlac.19284600106 /pdf 
[8] Takao, K.-i.; Munakata, R., and Tadano, K.-i. 2005. Recent Advances in Natural Product Synthesis by Using Intramolecular Diels-Alder Reactions. Chem. Rev. 105, 4779-4807. http://pubs.acs.org/doi/abs/10.1021/cr040632u

[9] Celius, T. C. 2010. Fast Hetero-Diels-Alder Reactions Using 4-Phenyl-1,2,4-triazoline-3,5-dione (PTAD) as the Dienophile. J. Chem. Edu. 87, 1236-1237. http://pubs.acs.org/doi/pdf/10.1021/ed100344g

[10] Coleman, W. F. 2010. Diels-Alder Reactions and the Structure of Transition States. J. Chem. Edu. 87, 1278-1279. http://pubs.acs.org/doi/pdf/10.1021/ed1009078

[11] Weizman, H.; Nielsen, C.; Weizman, O. S., and NematNasser, S. 2011. Synthesis of a Self-Healing Polymer Based on Reversible Diels-Alder Reaction: An Advanced Undergraduate Laboratory at the Interface of Organic Chemistry and Materials Science. J. Chem. Edu. 88, 11371140. http://pubs.acs.org/doi/pdf/10.1021/ed101109f

[12] Amin, S.; Barnes, A.; Buckner, C.; Jones, J.; Monroe, M.; Nurmomade, L.; Pinto, T.; Starkey, S.; Agee, B. M.; Crouse, D. J., and Swartling, D. J. 2015. Diels-Alder Reaction Using a Solar Irradiation Heat Source Designed for Undergraduate Organic Chemistry Laboratories. J. Chem. Edu. 92, 767-770. http://pubs.acs.org/doi/pdf/10.1021/ed500850c

[13] Sendlinger, S. C.; Metz C. R. 2010. Computational Chemistry for Chemistry Educators. J. Comput. Sci. Educ. 1, $28-32$.

http://www.shodor.org/media/content//jocse/submissions/sen dlinger2010/sendlinger2010 pdf

[14] More information of workshop, and detailed lectures and lab exercises can be found in the Computational Chemistry for Chemistry Educators website. http://www.computationalscience.org/ccce/

[15] Schmidt, J. R., and Polik, W. F. 2015 WebMO Version 16. http://www.webmo.net (Accessed 2013-2015).

[16] L. G. Wade, J.: Organic Chemistry; 8th Ed. ed.; Person Education, Inc., 2013. 